\title{
Specifics of interpersonal trust among people with different gender identities
}

\author{
Yury P. Zinchenko ${ }^{a}$, Olga Yu. Zotova ${ }^{b^{*}}$, Lyudmila V. Tarasova ${ }^{c}$ \\ a Faculty of Psychology, Lomonosov Moscow State University, Moscow, Russia \\ b Social Psychology Department, Liberal Arts University - University for Humanities, \\ Yekaterinburg, Russia \\ ${ }^{c}$ Human Resources Management Chair, Liberal Arts University-University for Humanities, \\ Yekaterinburg, Russia \\ *Corresponding author. E-mail: oiambusheva@mail.ru
}

Background. This study addresses a current problem relating to trust and the identification of gender differences in trust/mistrust manifestation. Gender identity is associated with cultural stereotypes and social roles, which facilitate the formation of trust in people. It acts as a significant integral meaning-based component of an individual's "I"conception, which contributes to the formation of trust in himself and the world around him.

Objective. To study features of trust/mistrust towards others in young people with different gender identities.

Design. The cross-gender-typical sample consisted of 179 representatives, 83 males and 96 females, ages 17 to $23(\mathrm{M}=19.34$ and $\mathrm{SD}=1.79)$. The techniques for collecting data included the MMPI, the Sex-Role Inventory by S. Bem, and the Trust/Mistrust towards Others questionnaire by A. Kupreychenko. The results were processed via the Mann-Whitney U Test, the Kruskal-Wallis H criterion, and cluster analysis.

Results. Criteria of trust/mistrust among the youth with different gender identities were identified, and basic types of trust - categoric, irrational-emotional, ambivalentcontradictory, and non-differentiated - were singled out. Irrespective of biological sex, bearers of different gender identities do not exhibit the same criteria to determine trust/ mistrust.

Conclusion. This study makes it possible to enrich our understanding of the role of social gender in the formation of interpersonal trust and differences in the foundations of trust toward others, in people with different gender identities. The empirical typology of trust in youth with different gender identities allows for using the typology in organizing psychological diagnostics, and for support and improvement of their interpersonal relations.

Keywords: gender identity, trust, trust/mistrust identity, gender differences, social roles 


\section{Introduction}

An individual's gender identity is built upon meanings and social categories attributed to males and females in his or her culture. When these cultural meanings are embedded into people's pictures of the world, gender identification becomes a part of their personalities. Thus, gender identity is the part of a multi-faceted "I"conception and a key aspect in the psychology of the personality (Epstein, 1973; Stets \& Burke, 2000).

The reasons for gender differences have been studied theoretically from different angles.

1. The socio-cultural approach to gender differences implies that gender differences result from social, cultural, psychological, and ecological factors. So, according to the biosocial construction model of W. Wood and A. Eagly (Wood \& Eagly, 2012), two factors determine gender differences: physical and sociocultural.

Gender division of labor is important since it contributes to the formation of cultural beliefs which are reflected in the process of socialization, social stereotypes, and social expectations. Female leaders, for example, are evaluated more negatively than male leaders, especially when the former demonstrate such masculine features such as domination, decisiveness, or self-confidence (Koenig et al., 2011). Men are not encouraged to show submission, compliance, and lack of egoism (Judge et al., 2012). As a result, men and women with pronounced gender identities have higher self-esteem, if these identities correspond to the gender standards accepted in their society (Witt \& Wood, 2010).

2. Evolutionary theory focuses on the impact of biological factors, in particular, on the formation of the mechanisms which man uses to adapt to a number of ecological problems. The idea is that natural selection stimulated the human brain so that it could develop various approaches appropriate for settling the problems which faced our ancestors (Tooby \& Cosmides, 2005): matchmaking, reproduction abilities, child-raising and protection, etc. These approaches differed according to sex.

From the perspective of the evolutionary approach, some factors that cannot be explained in terms of biology (for instance, culture) can also affect human development (Kenrick \& Luce, 2000).

This theory inspired studies into consumer behavior. Men, for example, are more likely to borrow money for immediate satisfaction of their needs, in order to attempt to enhance their status in the eyes of their rivals (Griskevicius et al., 2012), whereas women tend to purchase beauty goods to make themselves more attractive to the opposite sex (Hill et al., 2012).

Evolutionists assume that marital problems are also connected with certain encrusted gender differences, namely, a greater aggressiveness and proneness to risk-taking by males. According to the arguments of A. Fisher, P. Mosquera, and B. Ellis, such behavior used to be more functional for men than for women in their evolutionary past (Fischer \& Mosquera, 2001; Ellis et al., 2012).

Aggressiveness and acceptance of risk favor the formation of not only physical competence but also social status and men's sense of dignity. This behavior pattern heightens men's status by increasing their control over valuable resources, thus 
contributing to crucial male objectives: restriction of male competition and greater access to more females.

3. The physiological approach based on the study of sex hormones also provides insight into gender differences in behavior.

Research shows that testosterone, which is predominant in males, plays a significant role in the production of gender differences. Ethical norms prohibit the manipulation of sex hormones to study their impact on humans, so the majority of findings on this matter result from observations. However, there are novel approaches, including the study of fluctuations in the population's hormone level, which can be estimated by measuring the hormone level in blood serum or amniotic fluid (Cohen-Bendahan et al., 2005).

The most convincing evidence of the fact that hormones promote gender differences was obtained through observing children's play. For instance, V. Pasterski and his colleagues found that girls with inborn adrenal hyperplasia (a disorder characterized by an excessive androgen production) play games more typical of boys (Pasterski et al., 2005).

Thus, hormones affect gender identity and sexual orientation (Hines, 2006). Women with a higher androgen level are more aggressive (Mathews et al., 2009) and enjoy advantageous spatial orientation (Mueller et al., 2008).

Gender identity research was initiated in 1936 by the American psychologists L. Terman and C. Miles, who developed the bipolar Masculinity/Femininity scale in which male/female ratios were contrasted and interpreted dichotomically (Terman \& Miles, 1936).

Then, in the landmark paper on gender psychology, "Masculinity-femininity: An exception to a famous dictum?", Anne Constantinople criticized the treatment of masculinity and femininity as independent autonomous dimensions, and thus laid the foundation for the development of a new approach to understanding gender identity (Constantinople, 1973).

In 1974, S. Bem and J. Spence (Bem, 1974; Spence et al., 1975; Spence \& Helmreich, 1978) formulated a new theory of personality structure which offered several psychological variations of gender identity. This made it possible to avoid making the choice inherent in a bipolar dimension (i.e. either/or). At the end of the 1970s this approach suddenly became popular and stirred interest in gender identity studies (Eagly et al., 2012).

Scales to evaluate masculinity and femininity were worked out; they exploited personal traits borrowed from cultural male/female stereotypes. These models of gender identity were based on the evidence that gender stereotypes embrace both male and female characteristics (Broverman et al., 1972). The fact is that treating gender identity on the basis of traits is in many respects connected with the fact that the perception of the masculine and the feminine is often created by observing people's behavior (Uleman et al., 1996). Besides, male and female characteristics are easy to perceive (Broverman et al., 1972; Deaux \& Lewis, 1984). A. I. Dontsov and his co-authors stated that "social stereotypes reflect the typification of habitual estimates, expectations, viewpoints and prejudices. Such concepts of social bonds and relations are formed within a single culture and are stably shared by its members" (Dontsov \& Kabalevskaya, 2013). 
Following this research tradition, people were classified into four groups:

(a) masculine type - people with high values of masculinity and low values of femininity;

(b) feminine type - characterized by low values of masculinity and high values of femininity;

(c) androgynous type - high values of masculinity and femininity;

(d) non-differentiated type - low values of masculinity and femininity.

S. Bem promoted androgyny, arguing that the androgynous model of genderrole behavior provides for behavioral flexibility and guarantees success in realizing diverse social roles, which is beyond the capability of people with expressed exclusively male or female identity (Bem \& Lenney, 1976).

In addition, J. Spence and R. Helmreich (Spence \& Helmreich, 1978; Spence \& Helmreich, 1980) offered conditions for assessing masculinity and femininity, namely: instrumentality and expressiveness (emotionality).The gender-role model was also complemented with new scales which estimated the negative aspects of masculinity (for instance, ascendance) and femininity (for instance, easy crying and passiveness) (Spence et al., 1979).

Other popular personality models also considered gender differences. For example, measured according to the Big Five Personality Traits (extroversion, agreeableness, conscientiousness, neuroticism, and openness to experience) women, as a rule, are more friendly, more emotionally unstable, and can reach a consensus more quickly than men. Women's tendency to compassion is also markedly greater (Chapman et al., 2007; Costa et al., 2001; Weisberg et al., 2011).

Further research on gender identity has been done using other structures by which psychologists can evaluate an individual. Personal traits and human interests associated with sex, occupation, hobbies, etc. are actively explored. Thus, R. Lippa and S. Connelly (Lippa, 1991; Lippa \& Connelly, 1990) developed a method to diagnose gender identity using interest preferences. Gender identity acts as a significant integral meaning-based component of the "I"-conception, and is linked with cultural stereotypes and social roles (Eagly \& Wood, 2012; Wood \& Eagly, 2010). The male/female division of labor in society (Koenig \& Eagly, 2014), in turn, contributes to the formation of self-esteem and the level of trust in the world and one's self.

The view of B. Meyers-Levy, a consumer-demand researcher, who identifies differences in information processing, is worthy of attention (Meyers-Levy, 1989; Meyers-Levy \& Maheswaran, 1991; Meyers-Levy \& Sternthal,1991). In her words, women process information more completely than men, whereas men perceive information in a more selective manner.

In analyzing non-verbal manifestations of trust in men and women, T. P. Skripkina notes that men's expressions of trust can display "negative emotions" and ostentation; such specific elements as "expression of joy and active mimicking," as well as coquettishness, relate to female trust behavior. Androgynous women demonstrate trust through use of non-verbal characteristics typical of androgynous and masculine men, while non-verbal manifestation of trust by 
feminine women is seen via a relaxed posture and expression of admiration. The authors concluded that differences in non-verbal characteristics showing trust between masculine and feminine men and women are insignificant (Skripkina \& Bandourina, 2007).

Gender differences are also associated with moral judgments. In the opinion of Russian scholars A. Dontsov and E. Perelygina, "hierarchy is necessary because of the impracticability of a situation in which every person can be trusted at any time in accordance with secretly understood rules of ethics" (Dontsov \& Perelygina, 2014). Thus, women are more likely to follow those they perceive as having moral principles and ethical behavior (Jaffee \& Hyde, 2000; Walker, 2006). Women are more tolerant (Miller et al., 2008) and emphatic (Fehr et al., 2010). Moreover, women, as a rule, demonstrate a greater interest in participating in ecologically responsible actions (Zelezny et al., 2000), and activities that deal with ethical problems (doPaço \& Reis, 2012).

Men lie more often than women, especially when it comes to their own financial gains (Dreber \& Johannesson, 2008; Erat \& Gneezy, 2012), while women lie more often in situations when telling a lie can be beneficial for another person (Erat \& Gneezy, 2012). Women prefer greater altruism in their relationships with others (Gneezy et al., 2003; Gneezy \& Rustichini, 2004).

E. Kemp and his co-thinkers noted (Kemp et al., 2013) that women donate more willingly than men when a charitable event appeals to sympathy. Men, however, are more likely to take part in charity if their pride is involved.

Unlike men, women tend to overreact when corporate moral misconduct is discussed. They are more outraged by unethical corporate behavior, and their indignation can take the form of a corporate boycott (Lindenmeieretal.,2012).Compared to men, women more often accuse a company in a case where the company's product is harmful (Laufer \& Gillespie, 2004).

The results of trust research showed that women are more credulous than men (Feingold, 1994) and are more likely to trust in others, perhaps due to their greater striving for social affiliation (Beck et al., 2010; Buchan et al., 2008; Kosfeld et al., 2005).

However, gender differences in trust assessment in the context of e-mail correspondence and online games, which include a short and anonymous interaction, indicate greater trust by men (Midha, 2012). The women's lack of trust in online relationships is associated with their concerns about observation of confidentiality on the Web (Midha, 2012).Women are more anxious about the misuse of online information (Garbarino \& Strahilevitz, 2004).

The data from brain MRT show that, when participating in online trust-based relationships, more brain areas are activated in women than in men (Riedl et al., 2010). This conclusion coincides with the idea that women can process information in a more comprehensive manner. Men can place confidence in a person more often than women if they expect something in return.

It is worth mentioning that individuals who belong to groups that have been targets of discrimination historically (for example, minorities) are less likely to trust the majority of people (Terrell \& Barrett, 1979; Alesina \& La Ferrara, 2002; Glaeser et al., 2000). 
The study of psychological settings with the use of Rotter scale (Rotter, 1967) showed that a wide range of situations and potential groups in which people could develop trust, where people had more confidence in women than in men (Wright \& Sharp, 1979). A survey of auditors found that male clients were seen as less trustworthy than female clients. In Mexico, governmental officials formed female units of traffic cops, hoping that female officers would accept bribes less often than men (Treaster, 1999). Other international studies testify to the fact that corruption is not as widespread in countries which have greater participation of women in public life (Swamy et al., 2001; Dollar et al., 2001).

However, S. Jeanquart-Barone and U. Sekaran wrote (Jeanquart-Barone \& Sekaran, 1994) that male civil officers are trusted more than female leaders. In principle, the impact of gender differences on trust remains unclear; there are few papers where the given effects of interaction have been examined.

This brings the ambiguity of the male/female role in trust-based behavior to the fore. In addition, taking into account that each of the papers cited explored just one or two aspects of trust-based behavior, our insight into the degree of gender impact on trust is incomplete.

It should be noted that the complexity of this phenomenon resides in the fact that gender identity evolves and changes throughout an individual's life span (Tobin et al., 2010). Although many aspects of this study are applicable to all stages of life and development, we focused on the specifics of trust among young people with different gender identities. Youth is an important period in gender identity formation and gender personality socialization. Yet, this phenomenon is understudied theoretically and practically. "Self-perception is a powerful phenomenon that requires continual self-expression and discharge, but, simultaneously, it is indefinite, filled with the experiences of other people: parents, older friends, and other reputable people" (Zinchenko et al., 2016).

\section{Method}

The aim of this study was to explore the peculiarities of trust/mistrusts attitudes toward other people among young people with different gender identities. In order to realize the aim, the following tasks were set out to be addressed:

1. To correlate criteria of trust/mistrust in others among the youth with different gender identities;

2. To assess the intensity of ambivalent attitudes towards other people in people with different gender identities;

3. To design an empirical typology of trust/mistrust in others among the youth with different gender identities.

\section{Sample}

The sample was comprised of young people ages $17-23(\mathrm{M}=19.34$ and $\mathrm{SD}=1.79)$, with permanent residence in Yekaterinburg and the Sverdlovsk region. The total number was 179, including 83 males and 96 females. Seventy-four percent of the sample were students, and $26 \%$ were income-earning youth. 


\section{Tools and techniques}

The following tools were used to determine gender identity:

- Method of Multifaceted Personality Study (MMPS) - a variant of MMPI, adapted and standardized by F. B. Berezin - 5 scale;

- Sex-Role Inventory (S. Bem, adapted by M. V. Burakova and V. A. Labunskaya).

To identify the specifics of trust/mistrust attitudes toward other people, the Trust/Mistrust in Others questionnaire by A. B. Kupreychenko was used.

The data obtained was processed with the use of SPSS 20.0 package: descriptive statistics, the Mann-Whitney U Test, the Kruskal-Wallis $\mathrm{H}$ criterion, and the cluster analysis K-means method.

\section{Results}

The diagnostics of gender identity types showed the dominance of an androgynous personality type among the youth. In addition, one identity type- namely, nondifferentiated identity type - was not found in the sample examined. The results are presented in Table 1.

Table 1. Distribution of gender identity types in the sample, $\%$

\begin{tabular}{ccccc}
\hline \multirow{2}{*}{$\begin{array}{c}\text { Biological } \\
\text { sex }\end{array}$} & \multicolumn{4}{c}{ Gender Identity Types } \\
\cline { 2 - 5 } & Masculine & Feminine & Androgynous & Non-differentiated \\
\hline Male $(\mathrm{n}=83)$ & $37.7 \%$ & $9.3 \%$ & $53 \%$ & $0 \%$ \\
Female $(\mathrm{n}=96)$ & $8.75 \%$ & $31.88 \%$ & $59.37 \%$ & $0 \%$ \\
\hline
\end{tabular}

The application of Mann-Whitney statistics made it possible to identify significant differences in the criteria used to make assessments of interpersonal trust by groups of the opposite biological sex (Table 2). It was found that male participants'

Table 2. Comparative analysis of the significance of various criteria used to establish trust in others for male $(n=83)$ and female $(n=96)$ groups

\begin{tabular}{lccccc}
\hline \multirow{2}{*}{$\begin{array}{c}\text { Biological } \\
\text { sex }\end{array}$} & Reliability & Knowledge & $\begin{array}{c}\text { Friendly } \\
\text { Feeling }\end{array}$ & Unity & Calculation \\
\cline { 2 - 6 } Male & $\mathrm{M}=2.614 ;$ & $\mathrm{M}=2.205 ;$ & $\mathrm{M}=2.012 ;$ & $\mathrm{M}=1.928 ;$ & $\mathrm{M}=2.42 ;$ \\
& $\mathrm{SD}=1.06$ & $\mathrm{SD}=0.62$ & $\mathrm{SD}=0.63$ & $\mathrm{SD}=0.73$ & $\mathrm{SD}=0.885$ \\
Female & $\mathrm{M}=2.052 ;$ & $\mathrm{M}=2.10 ;$ & $\mathrm{M}=2.833 ;$ & $\mathrm{M}=2.093 ;$ & $\mathrm{M}=1.875 ;$ \\
UMann- & $\mathrm{SD}=1.059$ & $\mathrm{SD}=0.85$ & $\mathrm{SD}=0.816$ & $\mathrm{SD}=0.995$ & $\mathrm{SD}=0.886$ \\
$\begin{array}{l}\text { Whitney value } \\
\text { Level of } \\
\text { significance }\end{array}$ & 2839.000 & 3665.500 & 1977.000 & 3752.000 & 2620.000 \\
& & & & & \\
\hline
\end{tabular}


building of trust-based relationships was mainly guided by such criteria as Partner's Reliability and Calculation, while for young women, Fellow Feeling, - i.e. emotional attitude toward a partner-played the role of a fundamental trust factor. The results obtained correlate with A. B. Kupreychenko's findings.

Breaking up the male sample into masculine and feminine groups allowed us to detect the following differences in trust criteria estimates. At the statistically significant level $(\mathrm{p}<0.05)$, we found that, in shaping trust, masculine males rely more on Knowledge (U Mann-Whitney value $=64.000$ with $\mathrm{p}=0.000)$ and Calculation (U Mann-Whitney value $=68.500$ with $\mathrm{p}=0.001$ ), and less on Friendly Feeling (U Mann-Whitney value $=84.500$ with $\mathrm{p}=0.004)$ than feminine males. Matching of masculine and feminine subgroups did not produce statistically significant differences in the criteria of trust in other people.

The splitting-up of the female sample according to gender identity type also indicated differences in the criteria that feminine and masculine women use as basis for building up trust. We found that feminine women are mostly guided by the criteria of Friendly Feeling ( $U$ Mann-Whitney value $=73.500$ with $p=0.001$ ) and Unity (U Mann-Whitney value $=74.000$ with $\mathrm{p}=0.004)$, and less by the factor of Calculation ( $U$ Mann-Whitney value $=66.500$ with $p=0.000$ ) than masculine females. As in the case of the male sample, correlation of masculine and feminine women subgroups with the androgynous female subgroup did not produce any differences at the statistically significant level.

Further analysis provided the opportunity to single out criteria for building up trust-based relations with others in groups with different gender identities (Table 3). In line with the results obtained, trust criteria for masculine-type respondents are Reliability, Knowledge, and Calculation; for feminine-type respondents - Friendly Feeling, Unity, and Reliability; for androgynous type respondents - Reliability, Knowledge, and Friendly Feeling.

Table 3. Comparative analysis of the significance of the criteria determining trust in others in groups with different gender identities

\begin{tabular}{lccccc}
\hline $\begin{array}{c}\text { Gender } \\
\text { identity type }\end{array}$ & Reliability & Knowledge & $\begin{array}{c}\text { Trust criteria } \\
\text { Friendly } \\
\text { Feeling }\end{array}$ & Unity & Calculation \\
\hline Masculine & $\mathrm{M}=2.951 ;$ & $\mathrm{M}=2.707 ;$ & $\mathrm{M}=2.122 ;$ & $\mathrm{M}=1.780 ;$ & $\mathrm{M}=2.707 ;$ \\
& $\mathrm{SD}=0.630$ & $\mathrm{SD}=0.602$ & $\mathrm{SD}=0.748$ & $\mathrm{SD}=0.852$ & $\mathrm{SD}=0.750$ \\
Feminine & $\mathrm{M}=2.378 ;$ & $\mathrm{M}=1.757 ;$ & $\mathrm{M}=2.892 ;$ & $\mathrm{M}=2.622 ;$ & $\mathrm{M}=1.595 ;$ \\
& $\mathrm{SD}=0.492$ & $\mathrm{SD}=0.641$ & $\mathrm{SD}=0.906$ & $\mathrm{SD}=0.893$ & $\mathrm{SD}=0.551$ \\
Androgynous & $\mathrm{M}=2.476 ;$ & $\mathrm{M}=2.396 ;$ & $\mathrm{M}=2.267 ;$ & $\mathrm{M}=1.940 ;$ & $\mathrm{M}=2.198 ;$ \\
Valuex2 & $\mathrm{SD}=0.823$ & $\mathrm{SD}=0.801$ & $\mathrm{SD}=0.760$ & $\mathrm{SD}=0.936$ & $\mathrm{SD}=0.883$ \\
$\begin{array}{l}\text { Level of } \\
\text { significance }\end{array}$ & 18.976 & 30.337 & 15.837 & 18.170 & 33.499 \\
\hline
\end{tabular}

The analysis of the spread of indicators on the scale "Weaknesses of the Person You Trust in Most" in the groups under consideration showed trust ambivalence 
in representatives of the androgynous identity type.In this group this indicator made up 3.24points, while in the respondents with feminine and masculine identities, it constituted 0.89 and 1.24 points correspondingly. This result testifies to the fact that the bearers of an androgynous identity whom we studied evaluated the person they trusted in the most as unreliable, unpredictable, and one who stirs up ill feeling.

With the help of cluster analysis K-means method, we designed a typology of trust in others among the youth with different gender identities.

Type1 singled out those in the sample who had the highest differentiation of trust indicators with regard to a person who deserves to be trusted, and the person who is not worthy of confidence. Characteristic of this type is a reliance on high level of knowledge of people deserving trust, and those not justifying confidencei.e. this type's representatives consider themselves able to understand and to envisage other people's behavior. The person who failed to justify confidence is evaluated rather negatively in terms of his drawbacks, whereas the person enjoying trust lacks practically any weaknesses, and is considered reliable on the whole. This type can be conventionally named "Categoric." This type of trust was found in $31 \%$ of the respondents.

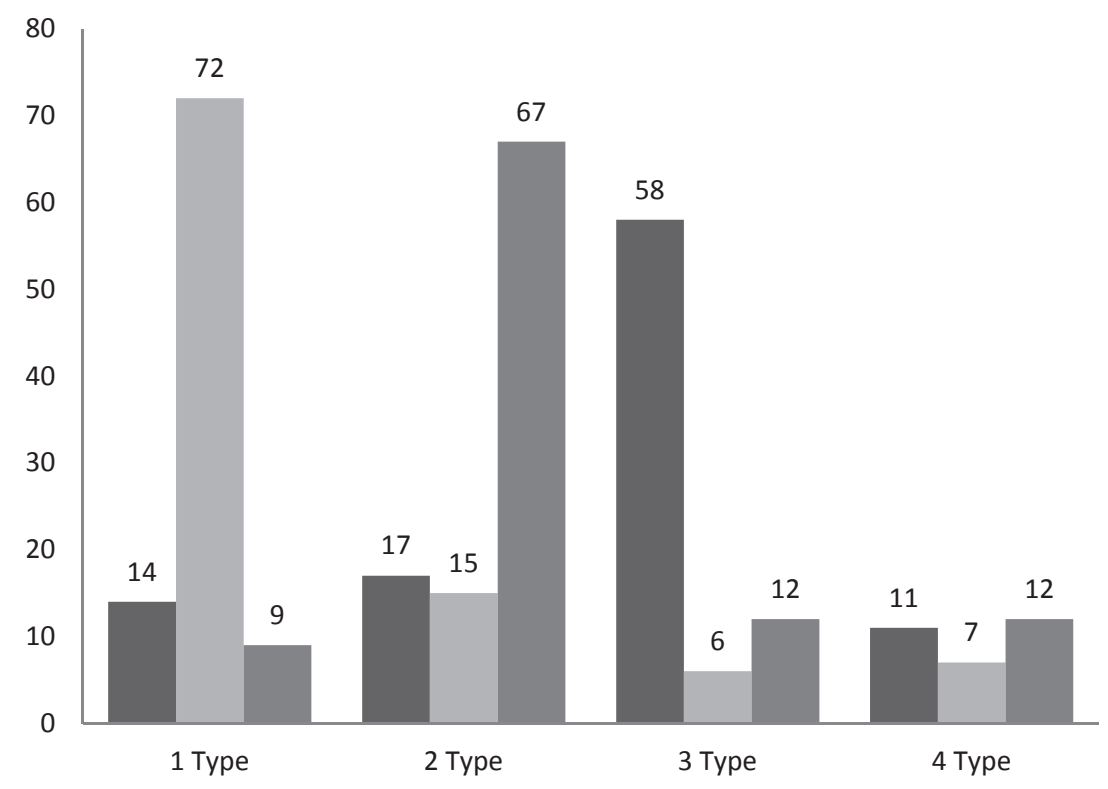

Figure 1. Representation of the types of trust in others among the groups of young people with different gender identities, $\%$

Type 2 was noted for giving the greatest significance to the trust criteria of Friendly Feeling, Reliability, and Unity. In other words, this type establishes trusting relationships on the basis of affection and emotional attachment. A confidence-inspiring person is seen as a personality with common interests, values, and world view. Representatives of this type are characterized by low indicators of Knowledge about the given person, i.e. the perceived similarity and common- 
ality are the result of affection, not of the objective state of things. Completely non-contradictory trust-based relations are typical of this type. Thus, this type can be labeled as "Irrationally Emotional." One-third of the sample fell under this category.

Type 3, the "Ambivalent-contradictory" type, represented a certain counterposition to Type 1 . The man who deserves trust is, at the same time, assessed as a person who is pleasant (Affection) and also as stirring up ill feeling (Weaknesses): as well-known and familiar (Knowledge) and alsounfamiliar, unpredictable, and unreliable .One quarter of the sample belonged to this type.

Type 4, the "Non-differentiated," was characterized by the lack of differentiation between persons deserving and non-deserving of trust. All indicators in these categories have close values. This type was found in $11 \%$ of the sample.

The distribution of the youth with different gender identities according to types of forming trust in others is shown in Figure 1.

\section{Discussion}

The survey was based on results from a sample which included three gender groups: masculine, feminine and androgynous. The sample was cross-gender typical, i.e. there were masculine females and feminine males. It is necessary to note that the data obtained showed the dominance of androgynous personality type among the youth. This is likely to be linked with the fact that this type is more adaptive to social reality, with its contradictory dictates and ever-changing conditions.

It was found that defining groups showing different criteria of trust in others according to social sex (gender identity) demonstrated more agreed results than the defining groups according to their biological sex. In other words, masculine males have more in common with masculine females in the criteria they use to shape trust-based relations than with feminine males. Thus, the results of the study make it evident that differences in the behavior of men and women, and features of their social positions, arise from differences in social sexual identification, not from biological sexual differences.

Bearers of different types exhibit different sets of criteria to establish underlying trust in others, irrespective of their biological sex. So, representatives of a femininetype identity tend to substitute Trust for Faith in their attitude toward a partner, and their level of trust is defined on the basis of feelings rather than the cognitive aspect. This type's representatives have the lowest number of significant trust criteria, compared with masculine and androgynous groups.

By contrast, representatives of the masculine identity type build up trust in others based on certain knowledge about them, their past acts, and mutual interest in establishing trust-based relationships. In this case, the relations are the result of rationalization. In other words, these representatives also fall back upon some substitute for trust-Calculation-rather than reliance on trust itself.

The androgynous identity type has a system of criteria synthesizing the criteria of the two above-mentioned groups. This system is represented by both rational grounding - Calculation, Knowledge - and emotional bonding -Affection. This can probably explain why an ambivalent, contradictory type of trust in others is more characteristic of representatives of this type of gender identity. 


\section{Conclusion}

Trust reflects confidence in the honesty and positive intentions of the people around you. Trust/mistrust is fundamental for shaping friendship, love, and respect. Trust acts as a basic premise of interpersonal, intra-group, and inter-group relationships. It is the condition for building up forms and types of relationships between people.

The results obtained with respect to trust criteria, as well as the empirical typology of trust in others among young people with different gender identities, enable us to take them into account in interpersonal interaction, and to use them in organizing psychological diagnostics, and providing support for an individual's interpersonal relations in a way adjusted for the individual's gender identity.

\section{Limitations and future research}

This study allowed us to gain a certain understanding of the social sex role in building interpersonal trust, and of differences in trust in others among people with different gender identities. However, this research does not exhaust all aspects of the problem of gender differences in the context of trust. The prospects for further study reside in considering and examining trust specifics among bearers of different gender identity types in various periods of their lives, i.e. searching for intragenerational differences. While analyzing interrelations between gender identity type and specifics of interpersonal trust, it is necessary to consider such factors as the individual's experience of trust-based relations,family status, and value-motivation spheres.

\section{Acknowledgements}

The article was written under the grant of the Russian Science Foundation (project № 16-18-00032).

\section{References}

Alesina, A., \& La Ferrara, E. (2002). Who trusts others? Journal of Public Economics, 85, 207 234. doi: 10.1016/S0047-2727(01)00084-6

Beck, T., Behr, P., \& Guettler, A. (2010). Gender and banking: Are women better loan officers? Review of Finance, 17(4), 1279-1321. doi: 10.1093/rof/rfs028

Bem, S.L., \& Lenney, E. (1976). Sex typing and the avoidance of crosssex behavior. Journal of Personality and Social Psychology, 33, 48-54. doi: 10.1037/h0078640

Bem, S.L. (1974). The measurement of psychological androgyny. Journal of Consulting and Clinical Psychology, 42, 155-162. doi: 10.1037/h0036215

Broverman, I.K., Vogel, S.R., Broverman, D.M., Clarkson, F.E., \& Rosenkrantz, P.S. (1972). Sexrole stereotypes: A current appraisal. Journal of Social Issues, 28, 59-78. doi: 10.1111/j.15404560.1972.tb00018.x

Buchan, N.R., Croson, R.T., \& Solnick, S. (2008). Trust and gender: An examination of behavior and beliefs in the Investment Game. Journal of Economic Behavior \& Organization, 68(3), 466-476. doi: 10.1016/j.jebo.2007.10.006

Chapman, B.P., Duberstein, P.R., Sörensen, S., \& Lyness. J.M. (2007). Gender differences in five factor model personality traits in an elderly cohort. Personality and Individual Differences, 43, 1594-1603. doi: 10.1016/j.paid.2007.04.028 
Cohen-Bendahan, C.C., van de Beek, C., \& Berenbaum, S.A. (2005). Prenatal sex hormone effects on child and adult sex-typed behavior: Methods and findings. Neuroscience \& Biobehavioral Reviews, 29(2), 353-384. doi: 10.1016/j.neubiorev.2004.11.004

Constantinople, A. (1973). Masculinity-femininity: An exception to a famous dictum? Psychological Bulletin, 80, 389-407. doi: 10.1037/h0035334

Costa, P.T., Terracciano, A., \& McCrae, R.R. (2001). Gender differences in personality traits across cultures: Robust and surprising findings. Journal of Personality and Social Psychology, 81, 322-331. doi: 10.1037/0022-3514.81.2.322

Deaux, K. \& Lewis, L.L. (1984). Structure of gender stereotypes: Interrelationships among components and gender label. Journal of Personality and Social Psychology, 46, 991-1004. doi: 10.1037/0022-3514.46.5.991

do Paço, A.M.F. \& Reis, R. (2012). Factors affecting skepticism toward green advertising. Journal of Advertising, 41(4), 147-155. doi: 10.1080/00913367.2012.10672463

Dollar, D., Fisman, R., \& Gatti, R. (2001). Are women really the "fairer" sex? Corruption and women in government. Journal of Economic Behavior and Organization, 46, 423-429. doi: 10.1016/S0167-2681(01)00169-X

Dontsov, A.I., \& Perelygina, E.B. (2014). Interpersonal confidence as a factor in the prevention of disorganized interaction. Psychology in Russia: State of the Art, 7(1), 42-49. doi: 10.11621/ pir.2014.0105

Dontsov, A.I., \& Kabalevskaya, A.I. (2013). Gender stereotypes among road users. Psychology in Russia: State of the Art, 6(3), 150-163. doi: 10.11621/pir.2013.0313

Dreber, A., \& Johannesson, M. (2008). Gender differences in deception. Economics Letters, 99(1), 197-199. doi: 10.1016/j.econlet.2007.06.027

Eagly, A.H., Eaton, A., Rose, S., Riger, S., \& McHugh, M. (2012). Feminism and psychology: Analysis of a half-century of research on women and gender. American Psychologist, 67, 211-230. doi: 10.1037/a0027260

Eagly, A.H., \& Wood, W. (2012). Social role theory. In P.A.M. Van Lange, A.W. Kruglanski, \& E.T. Higgins (Eds.), Handbook of theories in social psychology (Vol. 2, pp. 458-476). Thousand Oaks: Sage. doi: 10.4135/9781446249222.n49

Ellis, B.J., Del Giudice, M., Dishion, T.J., Figueredo, A.J., Gray, P., Griskevicius, V., \& Wilson, D.S. (2012). The evolutionary basis of risky adolescent behavior: Implications for science, policy, and practice. Developmental Psychology, 48(3), 598-632. doi: 10.1037/a0026220

Epstein, S. (1973). The self-concept revisited: Or a theory of a theory. American Psychologist, 28, 404-416. doi: 10.1037/h0034679

Fehr, R., Gelfand, M.J., \& Nag, M. (2010). The road to forgiveness: A meta-analytic synthesis of its situational dispositional correlates. Psychological Bulletin, 136(5), 894-914. doi: 10.1037/ a0019993

Feingold, A. (1994). Gender differences in variability in intellectual abilities: A cross-cultural perspective. Sex Roles, 30(1-2), 81-92. doi: 10.1007/BF01420741

Fischer, A.H., \& Mosquera, P.M.R. (2001). What concerns men? Women or other men?: A critical appraisal of the evolutionary theory of sex differences in aggression. Psychology, Evolution \& Gender, 3(1), 5-25. doi: 10.1080/14616660110049564

Garbarino, E., \& Strahilevitz, M. (2004). Gender differences in the perceived risk of buying online and the effects of receiving a site recommendation. Journal of Business Research, 57(7), 768-775. doi: 10.1016/S0148-2963(02)00363-6

Glaeser, E., Laibson, D., Scheinkman, J., \& Soutter, C. (2000). Measuring trust. Quarterly Journal of Economics, 115, 811-846. doi: 10.1162/003355300554926 
Gneezy, U., Niederle, M., \& Rustichini, A. (2003). Performance in competitive environments: Gender differences. The Quarterly Journal of Economics, 118(3), 1049-1074. doi: 10.1162/ 00335530360698496

Gneezy, U., \& Rustichini, A. (2004). Gender differences in competition at a young age. American Economic Review, 94(2), 337-381. doi: 10.1257/0002828041301821

Griskevicius, V., Tybur, J.M., Ackerman, J.M., Delton, A.W., Robertson, T.E., \& White, A.E. (2012). The financial consequences of too many men: Sex ratio effects on saving, borrowing, and spending. Journal of Personality and Social Psychology, 102, 69-80. doi: 10.1037/ a0024761

Hill, S.E., Rodeheffer, C.D., Griskevicius, V., Durante, K., \& White, E.A. (2012). Boosting beauty in an economic decline: Mating, spending, and the lipstick effect. Journal of Personality and Social Psychology, 103, 275-291. doi: 10.1037/a0028657

Hines, M. (2006). Prenatal testosterone and gender-related behaviour. European Journal of Endocrinology, 155(1), 115-121. doi: 10.1530/eje.1.02236

Jaffee, S., \& Hyde, J.S. (2000). Gender differences in moral orientation: A meta-analysis. Psychological Bulletin, 126(5), 703-726. doi: 10.1037/0033-2909.126.5.703

Jeanquart-Barone, S., \& Sekaran, U. (1994). Effects of supervisor's gender on American women's trust. Journal of Social Psychology, 134, 253-255. doi: 10.1080/00224545.1994.9711391

Judge, T.A., Livingston, B.A., \& Hurst, C. (2012). Do nice guys-and gals- really finish last? The joint effects of sex and agreeableness on income. Journal of Personality and Social Psychology, 102(2), 390-407. doi: 10.1037/a0026021

Kemp, E., Kennett-Hensel, P.A., \& Kees, J. (2013). Pulling on the heartstrings: Examining the effects of emotions and gender in persuasive appeals. Journal of Advertising, 42(1), 69-79. doi: 10.1080/00913367.2012.749084

Kenrick, D.T., \& Luce, C.L. (2000). An evolutionary life-history model of gender differences and similarities. In T. Eckes \& H.M. Trautner (Eds.), The developmental social psychology of gender (pp. 35-64). Hillsdale, NJ: Erlbaum.

Koenig, A.M., \& Eagly, A.H. (2014). Evidence for the social role theory of stereotype content: Observations of groups' roles shape stereotypes. Journal of Personality and Social Psychology, 107, 371-392. doi: 10.1037/a0037215

Koenig, A.M., Eagly, A.H., Mitchell, A.A., \& Ristikari, T. (2011). Are leader stereotypes masculine? A meta-analysis of three research paradigms. Psychological Bulletin, 137(4), 616-642. doi: 10.1037/a0023557

Kosfeld, M., Heinrichs, M., Zak, P.J., Fischbacher, U., \& Fehr, E. (2005). Oxytocin increases trust in humans. Nature, 435(7042), 673-676. doi: 10.1038/nature03701

Laufer, D., \& Gillespie, K. (2004). Differences in consumer attributions of blame between men and women: The role of perceived vulnerability and empathic concern. Psychology \& Marketing, 21(2), 141-157. doi: 10.1002/mar.10119

Lindenmeier, J., Schleer, C., \& Pricl, D. (2012). Consumer outrage: Emotional reactions to unethical corporate behavior. Journal of Business Research, 65(9), 1364-1373. doi: 10.1016/j. jbusres.2011.09.022

Lippa, R.A. (1991). Some psychometric characteristics of gender diagnosticity measures: Reliability, validity, consistency across domains, and relationship to the Big Five. Journal of Personality and Social Psychology, 61, 1000-1011. doi: 10.1037/0022-3514.61.6.1000

Lippa, R.A., \& Connelly, S. (1990). Gender diagnosticity: A new Bayesian approach to genderrelated individual differences. Journal of Personality and Social Psychology, 59, 1051-1065. doi: 10.1037/0022-3514.59.5.1051 
Mathews, G.A., Fane, B.A., Conway, G.S., Brook, C.G., \& Hines, M. (2009). Personality and congenital adrenal hyperplasia: possible effects of prenatal androgen exposure. Hormones and Behavior, 55(2), 285-291. doi: 10.1016/j.yhbeh.2008.11.007

Meyers-Levy, J. (1989). Gender differences in information processing: A selectivity interpretation. In P. Cafferata and A. Tybout (Eds.), Cognitive and Affective Responses to Advertising (pp. 219-260). Lexington, MA: Lexington Books.

Meyers-Levy, J., \& Maheswaran, D. (1991). Exploring differences in males' and females' processing strategies. Journal of Consumer Research, 18, 63-70. doi: 10.1086/209241

Meyers-Levy, J., \& Sternthal, B. (1991). Gender differences in the use of message cues and judgments. Journal of Marketing Research, 84-96. doi: 10.2307/3172728

Midha, V. (2012). Impact of consumer empowerment on online trust: An examination across genders. Decision Support Systems, 54(1), 198-205. doi: 10.1016/j.dss.2012.05.005

Miller, A.J., Worthington, Jr., E.L., \& McDaniel, M.A. (2008). Gender and forgiveness: A metaanalytic review and research agenda. Journal of Social and Clinical Psychology, 27(8), 843876. doi: $10.1521 /$ jscp.2008.27.8.843

Mueller, S.C., Temple, V., Oh, E., VanRyzin, C., Williams, A., Cornwell, B., \& Merke, D.P. (2008). Early androgen exposure modulates spatial cognition in congenital adrenal hyperplasia (CAH). Psychoneuroendocrinology, 33(7), 973-980. doi: 10.1016/j.psyneuen.2008.04.005

Pasterski, V.L., Geffner, M.E., Brain, C., Hindmarsh, P., Brook, C., \& Hines, M. (2005). Prenatal hormones and postnatal socialization by parents as determinants of male-typical toy play in girls with congenital adrenal hyperplasia. Child Development, 76(1), 264-278. doi: 10.1111/j.1467-8624.2005.00843.x

Riedl, R., Hubert, M., \& Kenning, P. (2010). Are there neural gender differences in online trust? An fMRI study on the perceived trustworthiness of eBay offers. Mis Quarterly, 34(2), 397428.

Rotter, J. (1967). A new scale for the measurement of interpersonal trust. Journal of Personality, 35, 651-665. doi: 10.1111/j.1467-6494.1967.tb01454.x

Skripkina, T.P., \& Bandourina, M.V. (2007). Osobennosti gendernyh neverbal'nyh patternov doveritelnogo otnoshenija $\mathrm{k}$ drugomu [Gender particularities of non-verbal patterns of the confidential relation to the Other]. Rossijskij psihologicheskij zhurnal [Russian Psychological Journal], 4(4), 30-39.

Spence, J.T., \& Helmreich, R.L. (1978). Masculinity \& femininity: Their psychological dimensions, correlates, and antecedents. Austin: University of Texas Press.

Spence, J.T., \& Helmreich, R.L. (1980). Masculine instrumentality and feminine expressiveness: Their relationships with sex role attitudes and behaviors. Psychology of Women Quarterly, 5, 147-163. doi: 10.1111/j.1471-6402.1980.tb00951.x

Spence, J.T., Helmreich, R.L., \& Holahan, C.K. (1979). Negative and positive components of psychological masculinity and femininity and their relationships to self-reports of neurotic and acting out behaviors. Journal of Personality and Social Psychology, 37, 1673-1682. doi: 10.1037/0022-3514.37.10.1673

Spence, J.T., Helmreich, R.L., \& Stapp, J. (1975). Ratings of self and peers on sex role attributes and their relation to self-esteem and conceptions of masculinity and femininity. Journal of Personality and Social Psychology, 32(1), 29-39. doi: 10.1037/h0076857

Stets, J.E., \& Burke, P.J. (2000). Identity theory and social identity theory. Social Psychology Quarterly, 63, 224-237. doi: 10.2307/2695870

Swamy, A., Knack, S., Lee, Y., \& Azfar, O. (2001). Gender and corruption. Journal of Development Economics, 64, 25-55. doi: 10.1016/S0304-3878(00)00123-1

Terman, L.M., \& Miles, C.C. (1936). Sex and personality: Studies in masculinity and femininity. New York, NY: McGraw-Hill. doi: 10.1037/13514-000 
Terrell, F., \& Barrett, R. (1979). Interpersonal trust among college students as a function of race, sex and socioeconomic class. Perceptual and Motor Skills, 48, 1194. doi: 10.2466/pms.1979. $48.3 \mathrm{c} .1194$

Tobin, D.D., Menon, M., Spatta, B.C., Hodges, E.V., \& Perry, D. G. (2010). The intrapsychics of gender: A model of self-socialization. Psychological Review, 117, 601-622. doi: 10.1037/ a0018936

Tooby, J., \& Cosmides, L. (2005). Conceptual foundations of evolutionary psychology. In D.M. Buss (Ed.), Evolutionary Psychology (pp. 5-67). Hoboken, NJ: John Wiley \& Sons.

Treaster, J. (1999). Equal opportunity in Mexico City; counting on women to be more honest than men. New York Times. Retrieved from http://www.nytimes.com/1999/08/15/weekinreview/world-equal-opportunity-mexico-city-counting-women-be-more-honest-thanmen.html

Uleman, J.S., Newman, L.S., \& Moskowitz, G.B. (1996). People as flexible interpreters: Evidence and issues from spontaneous trait inference. Advances in Experimental Social Psychology, 28, 211-279. doi: 10.1016/S0065-2601(08)60239-7

Walker, L.J. (2006). Gender and morality. In M. Killen \& J. Smetana (Eds.), Handbook of Moral Psychology (pp. 93-115). Mahwah, NJ: Erlbaum.

Weisberg, Y.J., DeYoung, C.G., \& Hirsh, J.B. (2011). Gender differences in personality across the ten aspects of the Big Five. Frontiers in Psychology, 2(178), 1-10. doi: 10.3389/ fpsyg.2011.00178

Witt, M.G., \& Wood, W. (2010). Self-regulation of gendered behavior in everyday life. Sex Roles, 62, 635-646. doi: 10.1007/s11199-010-9761-y

Wood, W., \& Eagly, A.H. (2002). A cross-cultural analysis of the behavior of women and men: Implications for the origins of sex differences. Psychological Bulletin, 128, 699-727. doi: 10.1037/0033-2909.128.5.699

Wood, W., \& Eagly, A.H. (2010). Gender. In S. T. Fiske, D. T. Gilbert, \& G. Lindzey (Eds.), Handbook of social psychology (Vol. 1, 5th ed., pp. 629-667). Hoboken, NJ: Wiley. doi: 10.1002/9780470561119.socpsy001017

Wright, T., \& Sharp, E. (1979). Content and grammatical sex bias on the interpersonal trust scale and differential trust toward women and men. Journal of Consulting and Clinical Psychology, 47, 72-85. doi: 10.1037/0022-006X.47.1.72

Zelezny, L.C., Chua, P.P., \& Aldrich, C. (2000). New ways of thinking about environmentalism: Elaborating on gender differences in environmentalism. Journal of Social Issues, 56(3), 443-457. doi: 10.1111/0022-4537.00177

Zinchenko, Yu.P., Zotova, O.Yu., Tarasova, L.V., \& Gaidamashko, I.V. (2016). The contamination of young people's notions about narcotics and psychoactive substances as a threat to psychological security. Psychology in Russia: State of the Art, 9(2), 39-53. doi: 10.11621/ pir.2016.0204

Original manuscript received January 30, 2017 Revised manuscript accepted April 12, 2017 First published online June 30, 2017 